师 



\title{
Wirtschaftsenglisch- Wörterbuch
}

\section{Englisch-Deutsch $\cdot$ Deutsch-Englisch}

\author{
Von \\ Universitätsprofessor \\ Dr. phil. Theodor van Bernem \\ Hon. Senior Fellow, University of Birmingham
}

6., durchgesehene Auflage

R. Oldenbourg Verlag München Wien 


\section{für Thea}

\section{Die Deutsche Bibliothek - CIP-Einheitsaufnahme}

\section{Bernem, Theodor van:}

Wirtschaftsenglisch-Wörterbuch : englisch-deutsch : deutschenglisch / von Theodor van Bernem. - 6., durchges. Aufl. München ; Wien : Oldenbourg, 2001

ISBN 3-486-25585-1

(C) 2001 Oldenbourg Wissenschaftsverlag GmbH

Rosenheimer Straße 145, D-81671 München

Telefon: (089) 45051-0

www.oldenbourg-verlag.de

Das Werk einschließlich aller Abbildungen ist urheberrechtlich geschützt. Jede Verwertung außerhalb der Grenzen des Urheberrechtsgesetzes ist ohne Zustimmung des Verlages unzulässig und strafbar. Das gilt insbesondere für Vervielfältigungen, Übersetzungen, Mikroverfilmungen und die Einspeicherung und Bearbeitung in elektronischen Systemen.

Gedruckt auf säure- und chlorfreiem Papier

Druck: R. Oldenbourg Graphische Betriebe Druckerei GmbH 